\title{
THE RECOGNITION OF CORONARY HEART DISEASE IN THE PRESENCE OF PULMONARY DISEASE
}

\author{
BY \\ HARRY A. REES, ARTHUR J. THOMAS, AND CHARLES ROSSITER \\ From the United Cardiff Hospitals (Llandough Hospital) and the Pneumoconiosis Research Unit \\ (Medical Research Council) \\ Received May 28, 1963
}

Coronary heart disease and pulmonary heart disease are common diseases occurring at the same age. The symptomatology of breathlessness and chest pain is similar. Thomas (1958) referred to the difficulties of differentiating the pleuropericardial pain of pulmonary disease from that of cardiac ischæmia. Radiology may help in the recognition of pulmonary disease but does not help in coronary heart disease except perhaps by demonstrating left ventricular enlargement when there is no other cardiac cause. Coronary heart disease may affect the pulmonary arteriolar bed and by producing pulmonary hypertension result in right ventricular hypertrophy (Thomas, James, and Owen, 1962). We have occasionally been surprised to discover significant coronary artery disease at necropsy when extensive cardio-respiratory investigation had not revealed its presence. Some workers consider that pulmonary heart disease can give rise to left ventricular hypertrophy (Roosenburg and Deenstra, 1954), but this is still debatable. It therefore seemed important to us to try to detect the presence of coronary heart disease in patients with pulmonary disease. Cardiography, using conventional and computer analysis, seemed best suited to this purpose.

\section{SubJeCtS AND Method}

We have studied the histories, necropsy reports, and cardiograms of 212 miners with chest disease, admitted to this hospital from 1955 to 1961 . A further 55 had been rejected because of other cardiac diseases, or inadequate clinical, cardiographic, or necropsy information. Many of these patients died at home but were referred for autopsy because of their occupation.

The autopsy findings were taken as definitive, the cases classified accordingly, pulmonary heart disease, coronary heart disease, both, or neither, and the cardiograms analysed against them.

Significant coronary heart disease was recorded when any part of the lumen of the macroscopic coronary tree was reduced to two-thirds or less. Pulmonary heart disease was recorded when right ventricular thickness was $5 \mathrm{~mm}$. or more. When it was less than $5 \mathrm{~mm}$. in the presence of significant coronary heart disease the case was classified as coronary heart disease alone. When the thickness was more than $5 \mathrm{~mm}$. in the

TABLE I

Cardiographic Criteria for Diagnosis of Pulmonary Heart Disease

\begin{tabular}{|c|c|}
\hline Major: one or more & Minor: two or more \\
\hline $\begin{array}{l}R \text { in } \operatorname{aVR}>4 \mathrm{~mm} . \\
R \text { in } V 1>7 \mathrm{~mm} . \\
S \text { in } V 1<2 \mathrm{~mm} . \\
R / S \text { in } V 1>1 \\
R \text { in } V 6<5 \mathrm{~mm} . \\
S \text { in } V 6>5 \mathrm{~mm} . \\
R V 1+S V 6>10.5 \mathrm{~mm} .\end{array}$ & $\begin{array}{l}\text { P waves }>2 \cdot 5 \mathrm{~mm} \text {. } \\
\text { Low amplitude (i.e. all waves } \leqslant 5 \mathrm{~mm} \text {.) in } \\
\text { standard leads } \\
\text { Right axis of }+110^{\circ} \\
\text { SI-III pattern } \\
R / S \text { in V6 }<1\end{array}$ \\
\hline
\end{tabular}


presence of significant coronary heart disease the case was classified as both. This was an arbitrary separation but it was felt that cardiographic differences might be found. In the absence of significant coronary heart disease and a right ventricular thickness less than $5 \mathrm{~mm}$. the case was classified as neither.

Table I shows the criteria used in the cardiographic diagnosis of pulmonary heart disease and Table II those of coronary heart disease. A combination of the criteria of pulmonary and coronary heart disease was used for cardiographic diagnosis in the both groups and their absence for the neither group.

Details of age distribution in each group (Table III), the predominant respiratory disease (Table IV), heart weight, and ventricular thickness (Table V) were recorded.

One of us (C.R.) analysed the data applying latent vector analysis to derive functions of the variables

TABLE II

Cardiographic Criteria for Diagnosis of Coronary Heart Disease

\begin{tabular}{ll}
\hline Left axis $-30^{\circ}$ to $-90^{\circ}$ & ST depression in lead $\mathrm{I}>1 \mathrm{~mm}$. \\
QI $>0.04$ sec. & T inverted in lead I \\
QaVF $>0.04$ sec. & T inverted in aVF \\
qR in aVL with T inverted & ST depression in V6>1 mm. \\
R/S in aVL with $T$ inverted & T inverted in V6 \\
\hline
\end{tabular}

(age and 19 other items, see Table VIII), that maximize the distance between the four groups of subjects in relation to the scatter within each group. For each individual only age and 19 of the present or absent criteria of the electrocardiograms could be used as the computer programme employed handled only 20 items.

\section{RESULTS}

Table III shows that death may occur at an early age from either pulmonary or coronary heart disease, particularly the former. The greatest mortality in all groups was from 56 years onwards.

TABLE III

Age at Death IN the Four Groups

\begin{tabular}{|c|c|c|c|c|c|c|c|c|}
\hline \multirow{2}{*}{ Age (yr.) } & \multicolumn{2}{|c|}{$\begin{array}{l}\text { Coronary heart } \\
\text { disease }\end{array}$} & \multicolumn{2}{|c|}{$\begin{array}{l}\text { Pulmonary heart } \\
\text { disease }\end{array}$} & \multicolumn{2}{|c|}{ Both } & \multicolumn{2}{|c|}{ Neither } \\
\hline & No. & $\%$ & No. & $\%$ & No. & $\%$ & No. & $\%$ \\
\hline $\begin{array}{l}31-35 \\
36-40 \\
41-45 \\
46-50 \\
51-55 \\
56-60 \\
61-65 \\
66-70 \\
71-75 \\
76-80 \\
\text { Totals }\end{array}$ & $\begin{array}{r}1 \\
2 \\
5 \\
9 \\
11 \\
12 \\
8 \\
3 \\
51\end{array}$ & $\begin{array}{r}2 \\
4 \\
10 \\
18 \\
22 \\
24 \\
16 \\
6\end{array}$ & $\begin{array}{r}4 \\
5 \\
10 \\
14 \\
33 \\
20 \\
5 \\
8 \\
2 \\
101\end{array}$ & $\begin{array}{r}4 \\
5 \\
10 \\
14 \\
33 \\
20 \\
5 \\
8 \\
2\end{array}$ & $\begin{array}{r}1 \\
2 \\
11 \\
16 \\
3 \\
1 \\
35\end{array}$ & $\begin{array}{r}3 \\
6 \\
31 \\
46 \\
9 \\
3\end{array}$ & $\begin{array}{r}1 \\
1 \\
4 \\
2 \\
7 \\
6 \\
3 \\
1 \\
25\end{array}$ & $\begin{array}{r}4 \\
4 \\
16 \\
8 \\
28 \\
24 \\
12 \\
4\end{array}$ \\
\hline
\end{tabular}

TABLE IV

Distribution of Predominant Respiratory Disease in the Four Groups

\begin{tabular}{|c|c|c|c|c|c|c|c|c|}
\hline \multirow{2}{*}{$\begin{array}{l}\text { Predominant respiratory } \\
\text { disease }\end{array}$} & \multicolumn{2}{|c|}{$\begin{array}{l}\text { Coronary heart } \\
\text { disease }\end{array}$} & \multicolumn{2}{|c|}{$\begin{array}{l}\text { Pulmonary heart } \\
\text { disease }\end{array}$} & \multicolumn{2}{|c|}{ Both } & \multicolumn{2}{|c|}{ Neither } \\
\hline & No. & $\%$ & No. & $\%$ & No. & $\%$ & No. & $\%$ \\
\hline $\begin{array}{l}\text { Simple pneumoconiosis } \\
\text { Progressive massive fibrosis } \\
\text { Bronchitis . . } \\
\text { Carcinoma of bronchus } \\
\text { Total .. } . . \\
\text {. }\end{array}$ & $\begin{array}{l}6 \\
26 \\
19 \\
51\end{array}$ & $\begin{array}{c}11 \cdot 8 \\
50 \cdot 9 \\
37 \cdot 3 \\
100\end{array}$ & $\begin{array}{r}5 \\
55 \\
40 \\
100\end{array}$ & $\begin{array}{c}5 \\
54 \cdot 4 \\
39 \cdot 6 \\
99\end{array}$ & $\begin{array}{l}2 \\
17 \\
\frac{16}{35}\end{array}$ & $\begin{array}{r}5 \cdot 7 \\
48 \cdot 6 \\
45 \cdot 7 \\
100\end{array}$ & $\begin{array}{r}4 \\
8 \\
11 \\
2 \\
25\end{array}$ & $\begin{array}{r}16 \\
32 \\
44 \\
8 \\
100\end{array}$ \\
\hline
\end{tabular}

Pulmonary heart disease group also contains one patient with essential pulmonary hypertension. 
TABLE V

Heart Weights and Ventricular Thicknesses

\begin{tabular}{|c|c|c|c|c|c|}
\hline \multicolumn{3}{|l|}{ Groups } & \multirow[t]{2}{*}{$\begin{array}{c}\text { Average heart weight } \\
\text { (g.) }\end{array}$} & \multirow[t]{2}{*}{$\begin{array}{l}\text { Average left } \\
\text { ventricular thickness } \\
\text { (mm.) }\end{array}$} & \multirow[t]{2}{*}{$\begin{array}{l}\text { Average right } \\
\text { ventricular thickness } \\
\text { (mm.) }\end{array}$} \\
\hline Neither & & & & & \\
\hline Simple pneumoconiosis & & & 300 & 10 & 4 \\
\hline Bronchitis $\ldots$. & $\ldots$ & $\ldots$ & $362 \cdot 5$ & $12 \cdot 4$ & $3 \cdot 5$ \\
\hline Progressive massive fibrosis & $\cdots$ & . & 380 & $13 \cdot 3$ & $4 \cdot 9$ \\
\hline \multicolumn{3}{|c|}{ Coronary heart disease and both groups } & & & \\
\hline Simple pneumoconiosis $\ldots$ & . & . & 422 & $16 \cdot 3$ & $6 \cdot 2$ \\
\hline Bronchitis $\ldots \quad \ldots \quad \ldots$ & . & . & 420 & $16 \cdot 9$ & $6 \cdot 5$ \\
\hline Progressive massive fibrosis & $\cdots$ & . & 400 & $14 \cdot 5$ & $7 \cdot 4$ \\
\hline \multicolumn{3}{|l|}{ Pulmonary heart disease } & & & \\
\hline Simple pneumoconiosis $\ldots$ & & . & 382 & $13 \cdot 6$ & $7 \cdot 4$ \\
\hline Bronchitis $\ldots$, . $\ldots$ & . & . & $422 \cdot 5$ & $12 \cdot 6$ & $7 \cdot 2$ \\
\hline Progressive massive fibrosis & . & . & $399 \cdot 7$ & $13 \cdot 1$ & $7 \cdot 1$ \\
\hline
\end{tabular}

Survival over the age of 70 years was more common with coronary heart disease alone or pulmonary heart disease alone than with both present ( 3 per cent only surviving). Twenty-one per cent of those with coronary heart disease alone lived more than 70 years whereas only 10 per cent with pulmonary heart disease alone did so. It was not possible to determine an ætiological relation between coronary heart disease and a particular respiratory disease (Table IV). The association seems to be one of chance.

Results of Comparison of Subjective Cardiographic Diagnosis with Necropsy Findings. Pulmonary heart disease was accurately diagnosed in 72 per cent, coronary heart disease in 84 per cent, both in 55 per cent, and neither present in 68 per cent. It was not surprising that the results were better in the coronary heart disease group, i.e. where the right ventricular thickness was less than $5 \mathrm{~mm}$., than in the both group. Combining these two groups the diagnostic accuracy was 70 per cent.

TABLE VI

Relative Frequencies of Cardiographic Indices in Pulmonary Heart Disease

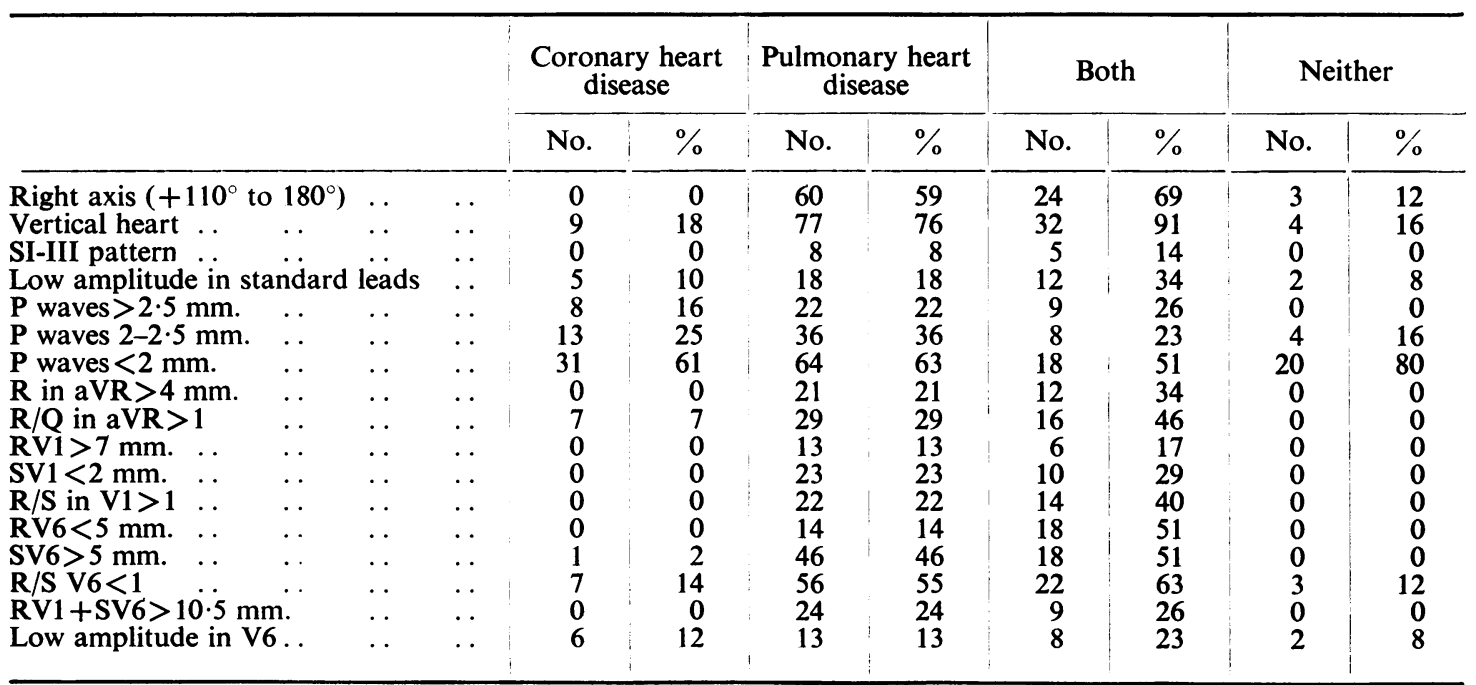


TABLE VII

Relative Frequencies of CARdiographic Indices in Coronary Heart Disease

\begin{tabular}{|c|c|c|c|c|c|c|c|c|c|}
\hline & & \multicolumn{2}{|c|}{$\begin{array}{l}\text { Coronary heart } \\
\text { disease }\end{array}$} & \multicolumn{2}{|c|}{$\begin{array}{c}\text { Pulmonary heart } \\
\text { disease }\end{array}$} & \multicolumn{2}{|c|}{ Both } & \multicolumn{2}{|c|}{ Neither } \\
\hline & & No. & $\%$ & No. & $\%$ & No. & $\%$ & No. & $\%$ \\
\hline 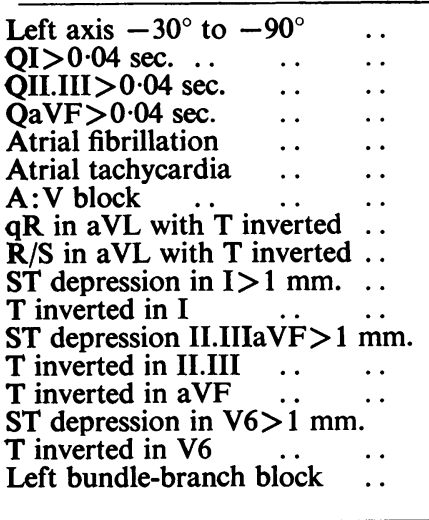 & 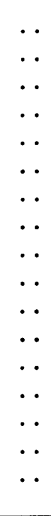 & $\begin{array}{r}19 \\
2 \\
6 \\
4 \\
4 \\
3 \\
4 \\
17 \\
6 \\
11 \\
9 \\
30 \\
5 \\
9 \\
28 \\
19 \\
1\end{array}$ & $\begin{array}{r}37 \\
4 \\
12 \\
8 \\
8 \\
6 \\
8 \\
33 \\
12 \\
22 \\
18 \\
59 \\
10 \\
18 \\
55 \\
37 \\
2\end{array}$ & $\begin{array}{r}8 \\
1 \\
1 \\
1 \\
2 \\
6 \\
5 \\
11 \\
2 \\
0 \\
1 \\
26 \\
2 \\
3 \\
11 \\
7 \\
1\end{array}$ & $\begin{array}{r}8 \\
1 \\
1 \\
1 \\
2 \\
6 \\
5 \\
11 \\
2 \\
0 \\
1 \\
26 \\
2 \\
3 \\
11 \\
7 \\
1\end{array}$ & $\begin{array}{r}11 \\
1 \\
3 \\
1 \\
1 \\
5 \\
2 \\
6 \\
2 \\
6 \\
10 \\
19 \\
4 \\
7 \\
12 \\
13 \\
0\end{array}$ & $\begin{array}{r}31 \\
3 \\
9 \\
3 \\
3 \\
14 \\
6 \\
17 \\
6 \\
17 \\
29 \\
54 \\
11 \\
20 \\
34 \\
37 \\
0\end{array}$ & $\begin{array}{l}6 \\
0 \\
0 \\
0 \\
0 \\
0 \\
1 \\
1 \\
1 \\
0 \\
0 \\
1 \\
0 \\
1 \\
4 \\
2 \\
0\end{array}$ & $\begin{array}{r}24 \\
0 \\
0 \\
0 \\
0 \\
0 \\
4 \\
4 \\
4 \\
0 \\
0 \\
4 \\
0 \\
4 \\
16 \\
8 \\
0\end{array}$ \\
\hline
\end{tabular}

Pulmonary Heart Disease Group. Indices like right axis deviation occurred in 12 per cent of the neither group, $\mathrm{R} / \mathrm{S}$ in V6 less than unity in 14 per cent of the coronary heart disease group, and in 12 per cent of the neither group and are non-specific. Pointed $P$ waves greater than $2.5 \mathrm{~mm}$. occurred in 16 per cent of the coronary heart disease group as well as in 22 per cent of the pulmonary heart disease group. It is recognized that $\mathbf{P}$ waves vary in height and form from day to day.

The criteria in Table I have proved specific for pulmonary heart disease. The most frequently occurring indices were $\mathrm{S}$ in V6 greater than $5 \mathrm{~mm}$. -46 per cent., RV1+SV6 greater than $10.5 \mathrm{~mm}$. -28 per cent, $R$ in aVR greater than $4 \mathrm{~mm}$. -21 per cent (Table VI). There were no false positive results in this group.

Coronary Heart Disease Group. These cases retained their identity on the cardiogram by virtue of the criteria listed in Table II and by the absence of the criteria of pulmonary heart disease. As may be seen from Table VII some of the criteria of coronary heart disease were noted in other groups, e.g. left axis, ST-T changes in V6 were both present in up to one-quarter of cases in other groups. $T$ inversion with upright $P$ waves in $\mathrm{aVL}$ whether the main complex was of $\mathrm{qR}$ or $\mathrm{R} / \mathrm{S}$ configuration was also non-specific.

ST depression in II, III, and aVF was commoner in the coronary heart disease group (59\%) than in the pulmonary heart disease group $(26 \%)$.

Atrial fibrillation occurred in 4 cases of this group, and in 2 cases, one transient and one persistent in the pulmonary heart disease group. Atrial tachycardias occurred with equal frequency in both groups-6 per cent.

Pulmonary Heart Disease and Co:onary Heart Disease. There were false positives due to the non-specificity of some of the coronary heart disease criteria. The dominant axis deviation was right 69 per cent, compared with left axis deviation 31 per cent. Atrial tachycardias were commoner in this group than in any of the others.

Respiratory Disease without Pulmonary Heart Disease or Coronary Heart Disease. The study of this group shows that some of the criteria accepted for the diagnosis of coronary heart disease can appear in this group.

Heart Weights and Ventricular Thicknesses (Table V). The heart weights and thicknesses of the coronary heart disease group and the group of coronary heart disease and pulmonary heart disease 
together have been combined. The heart weights in the combined coronary heart disease and the both groups was of the same order as the pulmonary heart disease group-about $400 \mathrm{~g}$. It is significant that there were 12 cases in the pulmonary heart disease group with left ventricular thickness greater than $15 . \mathrm{mm}$.

There were 7 cases of right bundle-branch block. There are obvious limitations to the ætiological diagnosis of this disorder using the present criteria, but it was felt they should be included in the whole series. The necropsy distribution of these cases was 2 in the pulmonary heart disease group, 1 in the coronary heart disease group, 3 in the both group, and 1 in the neither group. Barker and Valencia (1949) have suggested using R in V1 greater than $15 \mathrm{~mm}$. to indicate right ventricular hypertrophy in the presence of right bundle-branch block, but using this with our criteria has not proved diagnostic.

Results of Comparison of Objective Cardiographic Diagnosis with Necropsy findings. Computer Analysis. One of us (C.R.) further analysed the data by discriminant analysis to see if this would separate the groups sufficiently to provide some means of objective analysis. Using the first two latent roots, two discriminant functions were formed and were then rounded for future ease of computation. This rounding of the discriminants to one figure had a negligible effect on the significance. Table VIII lists and codes the criteria considered in this analysis; the resulting discriminants being: and

$$
\mathrm{X}=-0 \cdot 1 \times \mathrm{Age}+2 \mathrm{~A}+5 \mathrm{~B}+7 \mathrm{C}+3 \mathrm{E}+\mathrm{F}+2 \mathrm{H}+5 \mathrm{~J}+7 \mathrm{~K}-3 \mathrm{~L}-3 \mathrm{M}+2 \mathrm{~N}-8 \mathrm{P}+\mathrm{Q}-2 \mathrm{R}+4 \mathrm{~S}-2 \mathrm{~T}-2 \mathrm{U}
$$

$\mathrm{Y}=+0 \cdot 2 \times \mathrm{Age}+3 \mathrm{~B}+4 \mathrm{C}+3 \mathrm{D}-5 \mathrm{E}+6 \mathrm{~F}+2 \mathrm{G}+3 \mathrm{H}+2 \mathrm{~J}+\mathrm{K}+2 \mathrm{~L}-8 \mathrm{M}+3 \mathrm{~N}+9 \mathrm{P}+7 \mathrm{Q}+6 \mathrm{R}+11 \mathrm{~S}-5 \mathrm{~T}+3 \mathrm{U}$.

On these scales the averages for the four groups are shown in Table IX and the standard deviation within each group is 7.5 for both $X$ and $Y, X$ and $Y$ being virtually uncorrelated.

The calculated points $(X, Y)$ for each individual have been plotted in Fig. 1, and although there is some overlap between the groups it is apparent that the discriminants do in fact separate the groups well. The boundaries shown are the boundaries drawn if there were no knowledge of the proportion of individuals liable to fall into each group in the future, and they are, of course, only guides. Thus with an electrocardiogram, the values taken by $\mathrm{A}-\mathrm{U}$ above would be decided and $\mathrm{X}$ and $\mathrm{Y}$ would be calculated. This point would then be plotted and its position would indicate what would be likely to be found at autopsy. Thus if the point were $X=-12, Y=+29$, there would most probably be post-mortem evidence of coronary heart disease but not of pulmonary heart disease.

The result shown in Fig. 1 indicates a good separation of the calculated points and suggests that a method of this kind might well be of value in the future in identifying the results of cardiographic analysis without depending on subjective appreciation of patterns.

TABLE VIII

Data for LATENT Vector ANalysis

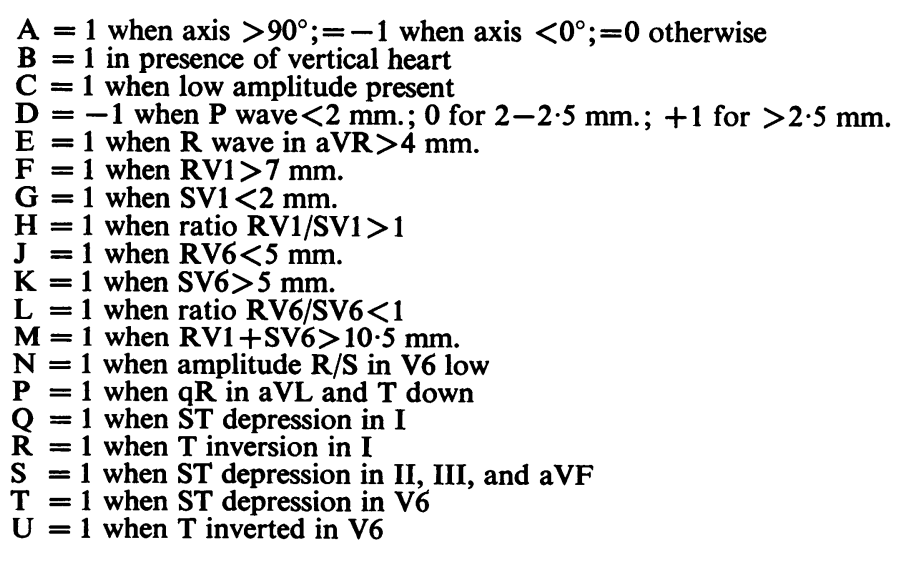




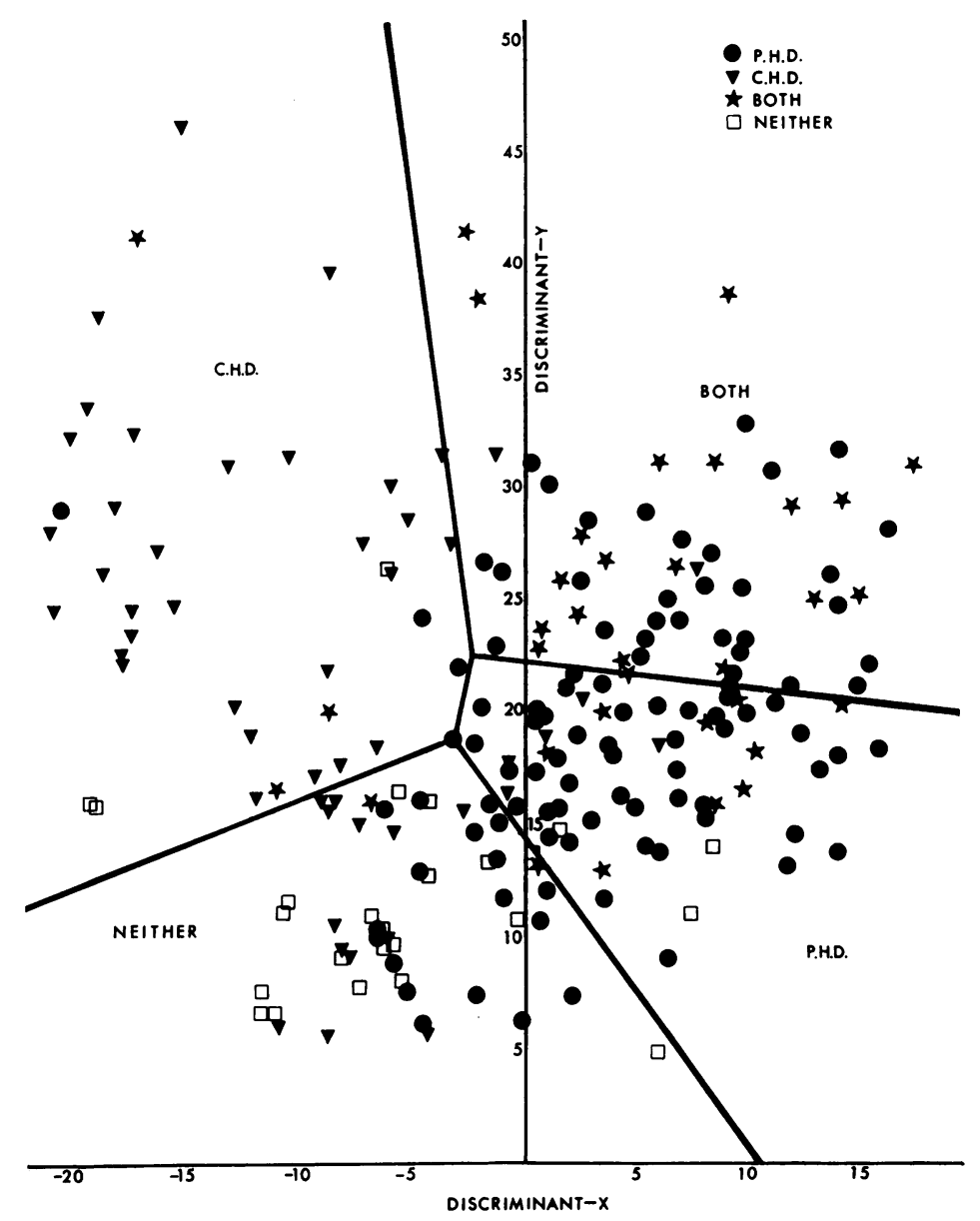

FIG. 1.-Calculated points for discriminants $\mathrm{X}$ and $\mathrm{Y}$ for each individual. (See text for explanation.)

\section{Discussion}

The object of this study was to ascertain whether coronary heart disease could be recognized in the presence of pulmonary disease. The results indicate a 70 per cent degree of accuracy combining the coronary heart disease and "both" groups, but false positives did occur. These were mainly related to ST-T changes in V6, and the administration of digitalis may have been responsible in some cases.

TABLE IX

\begin{tabular}{|c|c|c|c|c|c|c|c|}
\hline \multicolumn{6}{|c|}{ Groups } & \multicolumn{2}{|c|}{ Discriminants } \\
\hline & $\cdot$ & & & & & $x$ & $\mathbf{Y}$ \\
\hline $\begin{array}{l}\text { Pulmonar } \\
\text { Coronary } \\
\text { Both .. } \\
\text { Neither }\end{array}$ & $\begin{array}{c}\text { hear } \\
\text { eart } \\
\ldots \\
.\end{array}$ & $\begin{array}{l}\text { disease } \\
\text { isease } \\
\ldots \\
\ldots\end{array}$ & $\begin{array}{l}\ldots \\
\cdots \\
\cdots\end{array}$ & $\begin{array}{l}\ldots \\
\cdots \\
\cdots\end{array}$ & \begin{tabular}{l|l}
$\ldots$ & \\
$\cdots$ & \\
$\cdots$ & \\
$\cdots$ &
\end{tabular} & $\begin{array}{l}+4.2 \\
-9.6 \\
+4.8 \\
-5.5\end{array}$ & $\begin{array}{l}+18.6 \\
+22.0 \\
+23.9 \\
+11.5\end{array}$ \\
\hline
\end{tabular}


TABLE $X$

Comparison of Subjective Cardiographic Diagnosis with Autopsy Findings

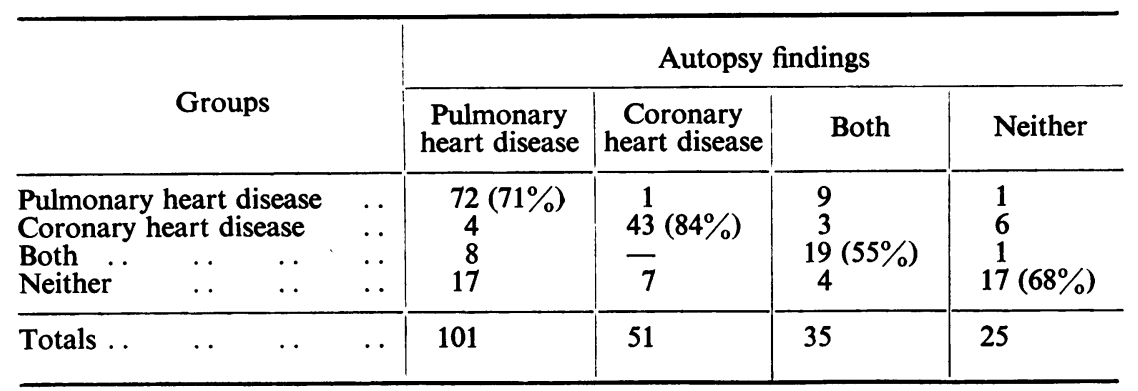

TABLE XI

Comparison of Diagnosis by Discriminant ANAlysis of CaRdiograms with Autopsy Findings

\begin{tabular}{|c|c|c|c|c|c|c|c|}
\hline & & & & \multicolumn{4}{|c|}{ Autopsy evidence } \\
\hline & & & & $\begin{array}{l}\text { Pulmonary } \\
\text { heart disease }\end{array}$ & $\begin{array}{c}\text { Coronary } \\
\text { heart disease }\end{array}$ & Both & Neither \\
\hline \multicolumn{3}{|c|}{$\begin{array}{l}\text { Pulmonary heart disease } \\
\text { Coronary heart disease }\end{array}$} & $\begin{array}{l}\ldots \\
\ldots \\
\ldots \\
\ldots\end{array}$ & $\begin{array}{l}46(46 \%) \\
20 \\
32 \\
2\end{array}$ & $\begin{array}{l}5 \\
31 \\
2 \\
13\end{array}$ & $\begin{array}{r}10 \\
3 \\
20 \\
2\end{array}(57 \%)$ & $\begin{array}{l}3 \\
3 \\
0 \\
19(76 \%)\end{array}$ \\
\hline Totals .. & .. & . & . & 101 & 51 & 35 & 25 \\
\hline
\end{tabular}

Total correct classification $116(54 \cdot 7 \%)$.

Average correct classification 59.9 per cent.

With certain reservations, e.g. the electrical axis and the heart position, the coronary heart disease cases retained their identity in the presence of respiratory disease. Low amplitude in the standard leads and in V6 in pulmonary heart disease also tends to modify the electrocardiogram when coronary heart disease is present.

The presence of left ventricular hypertrophy can be an important indication of coronary heart disease if there is no other cardiac cause present, but there were 12 cases ( 12 per cent) in the pulmonary heart disease group with left ventricular hypertrophy due to pulmonary heart disease alone. We feel that measurement of ventricular thickness is not as accurate as ventricular weight for the assessment of ventricular hypertrophy. In 67 cases of chronic cor pulmonale due to chronic lung disease Armen, Kantor, and Weiser (1958) found 2 instances of left ventricular hypertrophy. Unexplained left ventricular hypertrophy in the presence of pulmonary disease may therefore be due to "silent" coronary heart disease or pulmonary heart disease.

The arrhythmias encountered were atrial tachycardia, atrio-ventricular dissociation, and atrial fibrillation. Persistent atrial fibrillation is very uncommon in pulmonary disease, but it may be that paroxysmal atrial fibrillation occurs occasionally and passes unnoticed. It is our impression that atrial tachycardias in chronic pulmonary heart disease indicate a poor prognosis.

It is extremely difficult to determine any ætiological relation between coronary artery disease and pulmonary disease. It may be that there is a causal relation between the two, but we have found no evidence of this in the present analysis. When industrial disease is present with coronary disease the medico-legal problems multiply and it becomes important to recognize the presence of coronary artery disease particularly if it is causing disability. It is possible that continuing activity with increasing work load on the right ventricle might aggravate the effects of the coronary heart disease. 
It could also be argued that the poor nutritional state of patients with chronic pulmonary heart disease might protect them against coronary heart disease. This study has underlined the mortality risks at an early age of the two diseases, but selection of admission to hospital may have overemphasized this.

The diagnostic accuracy of the cardiogram in pulmonary heart disease has paralleled the findings of Phillips (1958), Milnor (1957), Armen et al. (1958), Widimský et al. (1960), and Sokolow and Lyon (1949). It does not seem possible to improve the accuracy over 71 per cent without introducing false positives. Using the present criteria for coronary heart disease an overestimate of the incidence of coronary heart disease is likely but it is difficult to know how this can be bettered.

Comparison of Tables $\mathrm{X}$ and XI shows that when heart disease was present there was a greater accuracy using subjective cardiographic diagnosis than with the discriminant analysis method. It must be remembered that the discriminant analysis was based on the presence or absence of criteria and not on absolute measurements. It has taken no account of the interactions between the variants. Even so we believe that this is one of the first successful attempts in this country to use cardiograms objectively as indicators of disease and we are engaged in a similar study using absolute measurements.

\section{SUMMARY}

A cardiographic study of the diagnosis of coronary heart disease in the presence of pulmonary disease has been made in 212 miners, analysing the cardiograms subjectively and by discriminant analysis against the autopsy evidence. A correct classification in all groups of 71.5 per cent was obtained by the standard subjective study compared with $54 \cdot 7$ per cent by discriminant analysis. Coronary heart disease in the presence of pulmonary disorder was noted in 69.5 per cent by standard methods compared with 59 per cent by discriminant analysis. The limitations of both methods are discussed.

We wish to thank Dr. Donald Ball (Miners Treatment Centre) and Dr. J. C. Gilson (Pneumoconiosis Research Unit, M.R.C.), Llandough Hospital for permission to study their patients, and the pathologists Professor J. Gough, Dr. W. R. L. James, Dr. T. Parry, and Dr. F. K. Storring.

This study was supported by a grant from the Endowment Fund of the United Cardiff Hospitals.

\section{REFERENCES}

Armen, R. N., Kantor, M., and Weiser, N. J. (1958). Pulmonary heart disease, with emphasis on electrocardiographic diagnosis. Circulation, 17, 164.

Barker, J. M., and Valencia, F. (1949). The precordial electrocardiogram in incomplete right bundle branch block. Amer. Heart J., 38, 376.

Milnor, W. R. (1957). Electrocardiogram and vectorcardiogram in right ventricular hypertrophy and right bundle branch block. Circulation, 16, 348.

Phillips, R. W. (1958). The electrocardiogram in cor pulmonale secondary to pulmonary emphysema: a study of 18 cases proved by autopsy. Amer. Heart J., 56, 352.

Roosenburg, J. G., and Deenstra, H. (1954). Bronchial-pulmonary vascular shunts in chronic pulmonary affections. Dis. Chest, 26, 664 .

Sokolow, M., and Lyon, T. P. (1949). The ventricular complex in right ventricular hypertrophy as obtained by unipolar precordial and limb leads. Amer. Heart J., 38, 273.

Thomas, A. J. (1958). Coronary heart disease in the presence of pulmonary disease. Brit. Heart J., 20, 83.

- James, W. R. L., and Owen, G. M. (1962). Abnormalities in the pulmonary arterioles in some cases of coronary artery disease. Brit. Heart J., 24, 110.

Widemský, J., Valach, A., Dejdar, R., Fejfar, Z., Vysloužil, Z., and Lukeš, M. (1960). The electrocardiographic pattern of right ventricular hypertrophy in cor pulmonale (due to pulmonary tuberculosis). Cardiologia (Basel), 36, 287. 